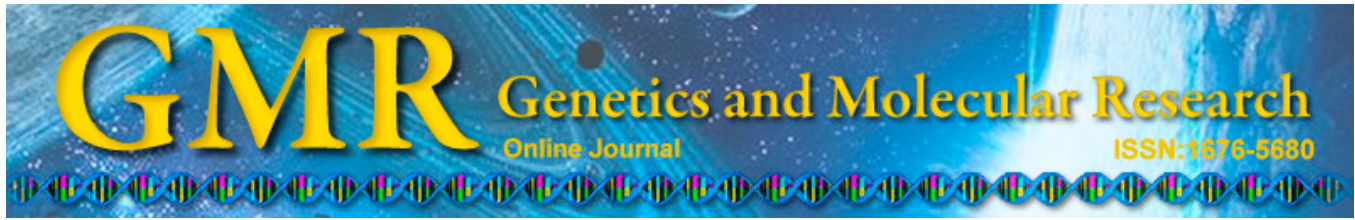

\title{
Duplication polymorphisms in exon 4 of K-casein gene in yak breeds/populations
}

\author{
S. Pingcuo ${ }^{1 *}$, J. Gao ${ }^{1 *}$, Z.R. Jiang ${ }^{2}$, S.Y. Jin ${ }^{1}$, C.Y. Fu ${ }^{1}$, X. Liu ${ }^{2}$, L. Huang ${ }^{1}$ \\ and Y.C. Zheng ${ }^{1}$ \\ ${ }^{1}$ College of Life Science and Technology, Southwest University for Nationalities, \\ Chengdu, China \\ ${ }^{2}$ Institute of Animal Science and Veterinary Medicine of Ganzi Prefecture, \\ Kangding, Sichuan, China \\ *These authors contributed equally to this study. \\ Corresponding author: Y.C. Zheng \\ E-mail: yucaizheng65@hotmail.com
}

Genet. Mol. Res. 14 (3): 10242-10248 (2015)

Received November 3, 2014

Accepted March 18, 2015

Published August 28, 2015

DOI http://dx.doi.org/10.4238/2015.August.28.8

\begin{abstract}
The objective of this study was to compare 12 bpduplication polymorphisms in exon 4 of the $\kappa$-casein gene among 3 breeds/populations of yak (Bos grunniens). Genomic DNA was extracted from yak blood or muscle samples $(\mathrm{N}=211)$ and a partial sequence of exon 4 of $\kappa$-casein gene was amplified by polymerase chain reaction. A polyacrylamide gel electrophoresis assay of the products (169 bp) revealed 2 variants. These variants differed in a 12-bp duplication of the nucleotide sequence corresponding to amino acids 147-150 (GluAla-Ser-Pro) or 148-151 (Ala-Ser-Pro-Glu). The genotype frequency and gene frequency of the $2 \kappa$-casein variants differed among the 3 yak breeds/populations. The long form of the $\kappa$-casein gene was the predominant allele, and the Jiulong yak showed the highest frequency of the short form variant of the $\kappa$-casein gene. In addition, 2 nucleotide differences resulting in amino acid substitutions were also identified in
\end{abstract}


yaks. These results are significant for designing a breeding strategy to improve the genetic makeup of yak herds.

Key words: Gene duplication; Genetic polymorphism; к-casein; Yak

\section{INTRODUCTION}

The $\kappa$-casein plays an essential role in stabilizing casein micelles and therefore has significant influence on the manufacturing properties of milk (Creamer et al., 1998). Genetic variants of $\kappa$-casein have been extensively studied in cattle at the protein and DNA levels, and numerous alleles have been revealed (Barroso et al., 1998; Prinzenberg et al., 1999; Gallinat et al., 2013). The association between milk coagulation properties and $\kappa$-casein variants and other casein variants have been reported previously (Bonfatti et al., 2010; Poulsen et al., 2013), and the genotyping of $\kappa$-casein and other caseins are important for determining milk processing properties.

Yak (Bos grunniens) milk contains high protein and fat contents and shows good coagulation properties (Zheng YC, Liu WJ and Jin SY, unpublished data). Several studies using the polymerase chain reaction (PCR)-single strand conformation polymorphism method have identified a 12-bp duplication in exon 4 of the yak $\kappa$-casein gene (Bai et al., 2008; Prinzenberg et al., 2008). This duplication represents a repeated nucleotide and an amino acid motif (4 amino acids) and accounted for $68 \%$ in 1 yak population ( $\mathrm{N}=21)$ (Prinzenberg et al., 2008). However, these studies used a small number of yaks. Because of the apparent amino acid differences, the 2 variants of $\kappa$-casein may differ in structure and function, thus influencing the coagulation and other processing properties of yak milk. The frequencies of $\kappa$-casein variants may differ among yak breeds. Therefore, in this experiment, we developed a PCR protocol followed by simple and rapid polyacrylamide gel electrophoresis separation to identify duplication variants of the $\kappa$-casein gene in 2 yak breeds and a yak population in order to investigate the distribution of duplication variants in the yak $\kappa$-casein gene. These data will be useful for yak breeding practice.

\section{MATERIAL AND METHODS}

\section{Animals and sample collection}

Three yak (B. grunniens) breeds/populations were studied in this experiment, including the Maiwa yak breed $(\mathrm{N}=72)$, Jiulong yak breed $(\mathrm{N}=72)$, and Changtai yak population $(\mathrm{N}=67)$ in the Sichuan Province of China. Yaks grazed on natural pasture at an altitude of approximately $3500 \mathrm{~m}$. The major distribution areas of the 3 yak breeds/populations were all at a distance of approximately $300 \mathrm{~km}$. A longissimus muscle sample was taken from each individual of Jiulong yaks and Maiwai yaks in slaughter houses, and blood samples were taken from Changtai yaks. All muscle samples were promptly frozen and stored at $-80^{\circ} \mathrm{C}$. This experiment was conducted according with the guidelines of the Chinese government for the use of experimental animals and EC Directive 86/609/EEC for animal experiments.

\section{Detection of duplication fragment in exon 4 of the yak k-casein gene}

Genomic DNA was isolated from the blood or skeletal muscles of the experimental yaks using the Universal Genomic DNA Extraction Kit Ver.3.0 (TaKaRa, Shiga, Japan). 
Qualified DNA was stored at $-20^{\circ} \mathrm{C}$ until further analysis.

To amplify the $\kappa$-casein gene fragment, a pair of PCR primers were designed based on the DNA sequence of yak א-casein (GenBank accession No. AY095311) as follows: Yakkcn169F: 5'-AATCCCTACCATCAATACC-3', Yakkcn-169R: 5'-TTAGACCGCAGTTGAAGT A-3', the expected fragment size was $169 \mathrm{bp}$. PCR amplifications were performed in standard conditions: denaturation at $94^{\circ} \mathrm{C}$ for $3 \mathrm{~min}$, then 37 cycles at $95^{\circ} \mathrm{C}$ for $30 \mathrm{~s}, 55^{\circ} \mathrm{C}$ for $30 \mathrm{~s}$, and $72^{\circ} \mathrm{C}$ for $30 \mathrm{~s} ; 72^{\circ} \mathrm{C}$ for $5 \mathrm{~min}$. PCR products were evaluated by $1.5 \%$ agarose gel electrophoresis and genotyped on $8 \%$ polyacrylamide gels using a Mini Protein 3 electrophoresis apparatus (Bio-Rad, Hercules, CA, USA). Electrophoresis was carried out in $1 \mathrm{X}$ TBE buffer (45 mM Tris-borate, $1 \mathrm{mM}$ EDTA, $\mathrm{pH} 8.0$ ) on ice at $110 \mathrm{~V}$ for $110 \mathrm{~min}$. The gels were silverstained and the images were acquired using a Versa Doc 1000 gel imaging system (Bio-Rad). The PCR products of the 2 variants of the $\kappa$-casein gene showed different mobilities on the gels. The Popgene version 1.32 software was used to calculate the allele frequency and genotype frequency of the $\kappa$-casein gene for each yak breed/population.

\section{Sequence assay of variants of the yak k-casein gene}

For the homozygous $\kappa$-casein gene, the PCR products of 2 yaks carrying different variants of the $\kappa$-casein gene were sequenced directly in both directions; for the heterozygous $\kappa$-casein gene, the amplified short form fragments $(\mathrm{N}=4)$ of the $\kappa$-casein gene were purified from agarose gels and cloned into the pMD 19-T Vector (TaKaRa), followed by transfection into Escherichia coli DH5a competent cells. Three to five positive clones were sequenced from both strands. Sequences were analyzed using DNAMAN Version 5.2.10 Demo (Lynnon BioSoft, San Ramon, CA, USA).

\section{RESULTS AND DISCUSSION}

\section{PCR amplification of partial sequence of the yak k-casein gene}

An expected 169-bp fragment was amplified using primers derived from the yak $\kappa$-casein gene as shown on the agarose gels (Figure 1A). The genotypes of these fragments were further determined by $8 \%$ polyacrylamide gel electrophoresis (Figure 1B), and 2 variants (A: long form, B: short form) were observed in all of the 3 yak breeds/populations.

Direct sequencing of the homozygous PCR products and gene cloning confirmed that the 169-bp fragment was a partial sequence of the $\kappa$-casein gene. The 2 variants showed a 12-bp duplication difference, representing a repeated nucleotide and amino acid motif (Figure 2). The duplication corresponds to the codons for amino acids 147-150 (Glu-Ala-Ser-Pro) or 148-151 (Ala-Ser-Pro-Glu). The protocol for genotyping the $\kappa$-casein gene in this study was simpler than using the PCR-single strand conformation polymorphism method (Bai et al., 2008; Prinzenberg et al., 2008).

Two single-nucleotide polymorphisms of the $\kappa$-casein gene were identified among yak individuals (Figure S1). The difference at amino acid 148 (Ala and Asp) was previously reported in bovine $\kappa$-casein A and B alleles (GenBank accession No. X14908), but had not been identified in yaks (Table 1). Because the 2 amino acids differ significantly in properties such as charge and molecular weight, this substitution may affect the function of $\kappa$-casein as well as the $\kappa$-casein derived antibacterial peptide (Malkoski et al., 2001). In addition, the 
amino acid change at position136 (Thr and Ile) was observed in both yaks (Table 1) and cattle (GenBank accession No. X14908 and AF123251), and Ala at this position appeared to be predominant in most yaks (Table 1), which is different from in cattle (Prinzenberg et al., 2008).
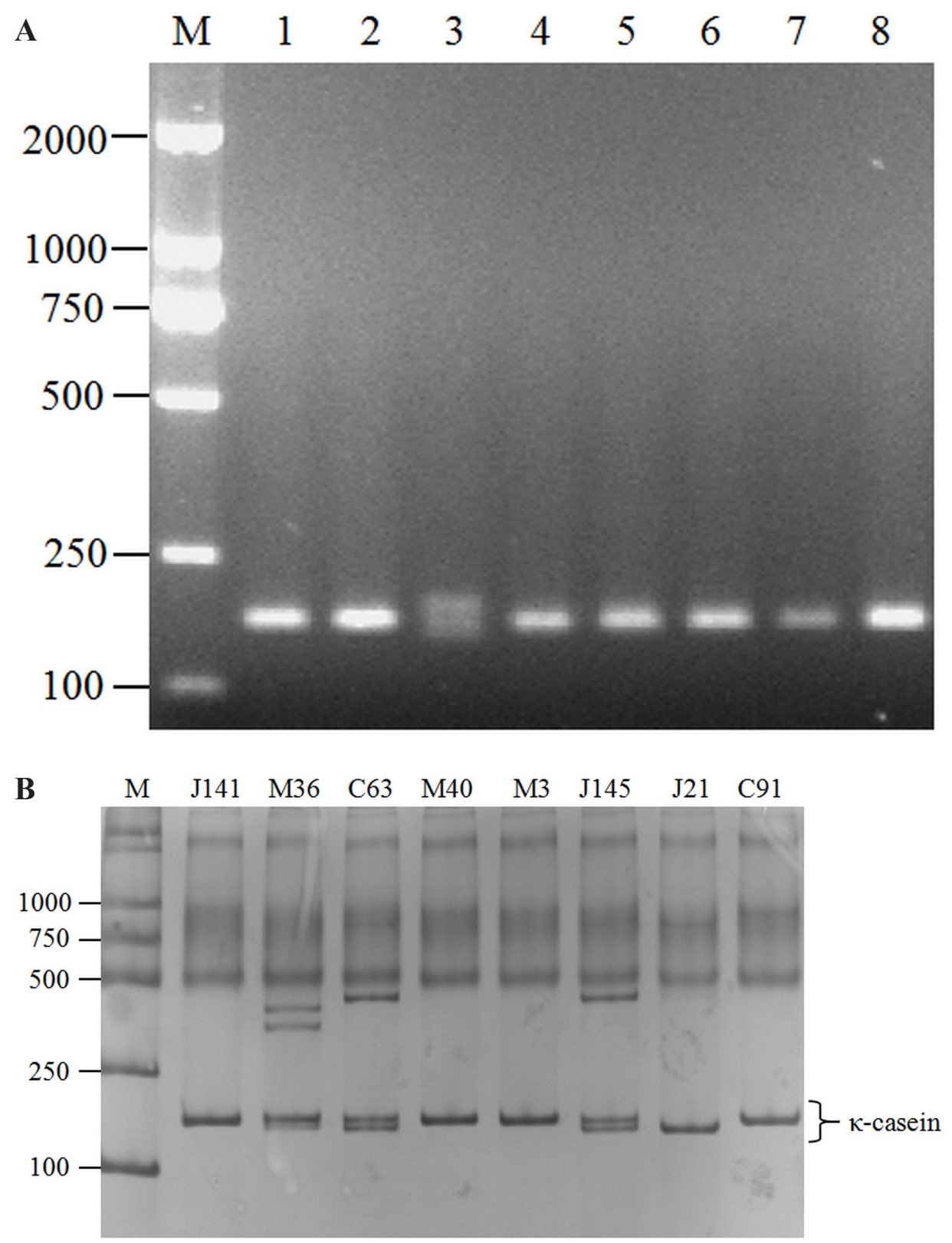

Figure 1. Agarose gel (A) and polyacrylamide gel (B) electrophoresis of PCR products after amplifying partial sequence in exon 4 of the yak $\kappa$-casein gene. Lane $M=2000$-bp DNA ladder marker (bp); other lanes represent different yak samples. 


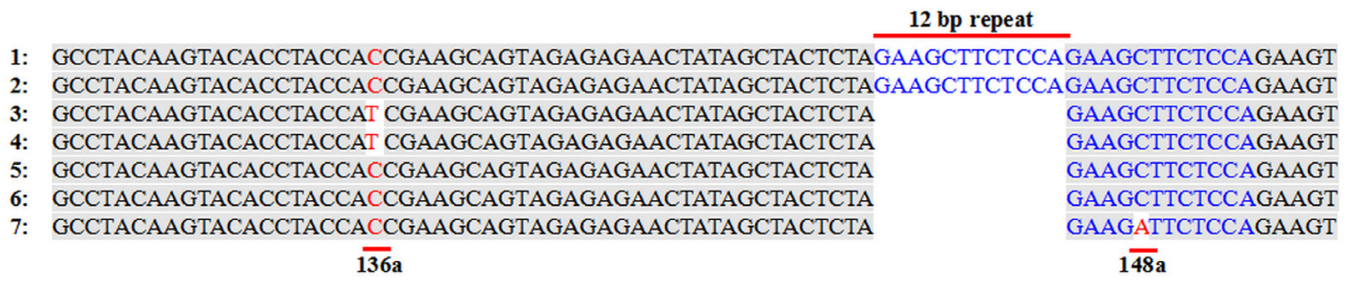

Figure 2. Alignment of partial sequence of the $\kappa$-casein gene of yaks. The 2 variants of the $\kappa$-casein gene showed a difference of a 12-bp nucleotide duplication (GAA GCT TCT CCA) as shown on the top of the figure, representing a repeated amino acid motif from 147-150 (Glu-Ala-Ser-Pro) or 148-151 (Ala-Ser-Pro-Glu). The 136a and 148a represent the amino acid positions of mature $\kappa$-casein encoded by 2 codons, respectively. 1: Yak (GenBank accession No. AY095311), 2: Maiwa-19, 3: Jiulong-22, 4: Jiulong-59, 5: Changtai-23, 6: Changtai-50, 7: Changtai-99.

Table 1. Difference in deduced amino acids in exon 4 of the yak $\kappa$-casein gene.

\begin{tabular}{lllll}
\hline Yak or GenBank accession No. & \multicolumn{3}{c}{ Amino acid position of k-casein } & \multirow{2}{*}{ GenBank submitter } \\
\cline { 2 - 4 } & 136 & $147-150$ & 148 & \\
\hline AH009225.2 & Thr (ACC) & & Ala (GCT) & Fan et al. \\
AF030326 & Thr & Glu-Ala-Ser-Pro & Ala & Ward et al. \\
AY095311 & Thr & Glu-Ala-Ser-Pro & Ala & Prinzenberg et al. \\
AY095312 & Thr & & Ala & Prinzenberg et al. \\
EF565131 & Thr & Glu-Ala-Ser-Pro & Ala & Bai et al. \\
Maiwa-19 & Thr & & Ala & Present study \\
Changtai-23 & Thr & & Ala & Present study \\
Jiulong-22 & Ile (ATC) & & Asp (GAT) & Present study \\
Changtai-59 & Thr & & Present study \\
\hline
\end{tabular}

Maiwa-19 to Changtai-59 represent 4 yak individuals of different breeds/populations. Amino acid positions are compared with mature bovine $\kappa$-casein. Position of the duplication is indicated as amino acid 147-150, although 148-151 was also possible. The 3 letters in the bracket represent the codons of corresponding amino acids. Bold letters at positions 136 and 148 represent the changed amino acids (codons).

\section{Genotyping of the к-casein gene in three yak breeds/populations}

Based on the results of polyacrylamide gel electrophoresis analysis (Figure 1B), the genotype frequency and gene frequency of the 2 variants of the $\kappa$-casein gene differed among the 3 yak breeds/populations (Table 2). The B variant (long form) of the $\kappa$-casein gene was the predominant allele, while the Jiulong yaks showed the highest frequency of the A variant (short form). These characteristics suggest that breeding isolation occurred between Jiulong yaks and Maiwa yaks or Changtai yaks, as the immigration of foreign yak breeds was forbidden and pure breeding as a traditional method was used in the breeding practice of Jiulong yaks.

Milk protein composition traits are associated with protein genetic variants (Huang et al., 2012). Yak $\kappa$-casein may exist as several variants because of the occurrence of 4 amino acid duplication as well as other amino acid substitutions as shown in Table 1 and other studies (Prinzenberg et al., 2008; Bai et al., 2008). Therefore, it is necessary to compare the structures and functions of different genetic variants of yak $\kappa$-casein, particularly the 2 duplication variants. However, the characteristics of yak $\kappa$-casein have not been well-documented. Yak milk shows good coagulation following the addition of chymosin, and no individual showed noncoagulating milk (Zheng YC, Liu WJ and Jin SY, unpublished data) as in bovine milk (Okigbo et al., 1985; Poulsen et al., 2013). This is an advantage of yak milk during cheese-making, although the related mechanism remains unclear. The coagulation property of bovine milk is 
likely associated with milk protein genetic variants (Jensen et al., 2012a, 2012b). Genotyping of yak $\kappa$-casein will be useful for determining its functions.

Although the 12-bp nucleotide sequence duplication has been reported previously in yaks (Prinzenberg et al., 2008), this study surveyed polymorphisms in a large number of yaks from 3 breeds/populations and revealed useful information. It has been speculated that the loss of the 12-bp nucleotide sequence duplication led to the ancestral allele of the $\kappa$-casein gene (Prinzenberg et al., 2008). The higher gene frequency of the $\kappa$-casein gene A allele (short form) in Jiulong yaks compared to in Maiwa and Changtai yaks (Table 2) suggests that this breed contains the original allele of the $\kappa$-casein gene. In fact, Jiulong yak is the largest yak breed in body size (Wiener et al., 2003), and may show lower diversity than other yak breeds (Zheng et al., 2006), which is likely related to their distribution region and breeding practice. In this study, we developed a simple protocol for analyzing the $12 \mathrm{bp}$-duplication polymorphisms in exon 4 of the $\kappa$-casein gene. Analysis of $\kappa$-casein gene polymorphisms in 3 yak breeds/populations will allow monitoring of the inbreeding level and can help in designing a breeding strategy for improving the genetic makeup of yak herds. Additionally, our results are important for determining the evolutionary and functional characteristics of the yak $\kappa$-casein gene.

Table 2. Genotype and gene frequencies of 2 variants of the yak $\kappa$-casein gene.

\begin{tabular}{|c|c|c|c|c|c|c|}
\hline \multirow[t]{2}{*}{ Breed/population } & \multirow[t]{2}{*}{$\mathrm{N}$} & \multicolumn{3}{|c|}{ Genotype frequency } & \multicolumn{2}{|c|}{ Gene frequency } \\
\hline & & $\mathrm{AA}$ & $\mathrm{AB}$ & $\mathrm{BB}$ & $\mathrm{A}$ & B \\
\hline Changtai yak & 67 & 1 & 11 & 55 & 0.097 & 0.903 \\
\hline Maiwa yak & 72 & 1 & 16 & 55 & 0.125 & 0.875 \\
\hline Jiulong yak & 72 & 3 & 32 & 37 & 0.264 & 0.736 \\
\hline
\end{tabular}

A, short form; B, long form with 12-bp nucleotide sequence duplication.

\section{ACKNOWLEDGMENTS}

Research supported by the Special Fund for Agro-Scientific Research, Ministry of Agriculture of the People's Republic of China (\#201203010), and the Animal Science Discipline Program of Southwest University for Nationalities (\#2011XWD-S0905).

\section{Supplementary material}

\section{REFERENCES}

Bai WL, Yin RH, Zhao SJ, Zheng YC, et al. (2008). Characterization of a kappa-casein genetic variant in the Chinese yak, Bos grunniens. J. Dairy Sci. 91: 1204-1208.

Barroso A, Dunner S and Cañón J (1998). Technical note: Detection of bovine kappa-casein variants A, B, C, and E by means of polymerase chain reaction-single strand conformation polymorphism (PCR-SSCP). J. Anim. Sci. 76: 1535-1538.

Bonfatti V, Di Martino G, Cecchinato A, Degano L, et al. (2010). Effects of beta-kappa-casein (CSN2-CSN3) haplotypes, beta-lactoglobulin (BLG) genotypes, and detailed protein composition on coagulation properties of individual milk of Simmental cows. J. Dairy Sci. 93: 3809-3817.

Creamer LK, Plowman JE, Liddell MJ, Smith MH, et al. (1998). Micelle stability: kappa-casein structure and function. J. Dairy Sci. 81: 3004-3012.

Gallinat JL, Qanbari S, Drögemüller C, Pimentel EC, et al. (2013). DNA-based identification of novel bovine casein gene variants. J. Dairy Sci. 96: 699-709.

Huang W, Peñagaricano F, Ahmad KR, Lucey JA, et al. (2012). Association between milk protein gene variants and protein composition traits in dairy cattle. J. Dairy Sci. 95: 440-449. 
Jensen HB, Holland JW, Poulsen NA and Larsen LB (2012a). Milk protein genetic variants and isoforms identified in bovine milk representing extremes in coagulation properties. J. Dairy Sci. 95: 2891-2903.

Jensen HB, Poulsen NA, Andersen KK, Hammershøj M, et al. (2012b). Distinct composition of bovine milk from Jersey and Holstein-Friesian cows with good, poor, or noncoagulation properties as reflected in protein genetic variants and isoforms. J. Dairy Sci. 95: 6905-6917.

Malkoski M, Dashper SG, O’Brien-Simpson NM, Talbo GH, et al. (2001). Kappacin, a novel antibacterial peptide from bovine milk. Antimicrob. Agents Chemother. 45: 2309-2315.

Okigbo LM, Richardson GH, Brown RJ and Ernstrom CA (1985). Effects of pH, calcium chloride, and chymosin concentration on coagulation properties of abnormal and normal milk. J. Dairy Sci. 68: 2527-2533.

Prinzenberg EM, Krause I and Erhardt G (1999). SSCP analysis at the bovine CSN3 locus discriminates six alleles corresponding to known protein variants (A, B, C, E, F, G) and three new DNA polymorphisms (H, I, A1). Anim. Biotechnol. 10: 49-62.

Prinzenberg EM, Jianlin H and Erhardt G (2008). Genetic variation in the kappa-casein gene (CSN3) of Chinese yak (Bos grunniens) and phylogenetic analysis of CSN3 sequences in the genus Bos. J. Dairy Sci. 91: 1198-1203.

Poulsen NA, Bertelsen HP, Jensen HB, Gustavsson F, et al. (2013). The occurrence of noncoagulating milk and the association of bovine milk coagulation properties with genetic variants of the caseins in 3 Scandinavian dairy breeds. J. Dairy Sci. 96: 4830-4842.

Ward TJ, Honeycutt RL and Derr JN (1997). Nucleotide sequence evolution at the kappa-casein locus: evidence for positive selection within the family Bovidae. Genetics 147: 1863-1872.

Wiener G, Han JL and Long RJ (2003). The Yak (second edition). The Regional Office for Asia and the Pacific of the Food and Agriculture Organization of the United Nations, Bangkok.

Zheng YC, Zhao XB, Jin SY, Peng XW, et al. (2006). Genetic polymorphisms of milk epithelial mucin of yaks. Prog. Nat. Sci. 16: 1222-1226. 